\title{
EDUCAR É CONSTRUIR IMAGENS: CONTRIBUIÇÃO DO CINEMA PARA UM ENSINO JURÍDICO DE QUALIDADE
}

\author{
José Rubens Demoro Almeida*
}

\begin{abstract}
Resumo: A reflexão sobre a didática e a pedagogia do professor no curso de Direito impõese como urgente. Tradicionalmente formalista, a prática jurídica ressente-se de um arejamento de ideias e de concepções menos dogmáticas, menos repetitivas, menos ritualistas. $\mathrm{O}$ ensino jurídico tem boa parcela de contribuição para a formação e manutenção de concepções tradicionais do fenômeno jurídico. Uma abordagem mais ampla do direito, questionadora e reflexiva, pode ser atingida pela mudança de hábitos tradicionais da aula de direito, expositiva, magistral. O professor de direito deve ser um agente e sujeito de um processo educacional de construção coletiva de saberes, de formação de alunos críticos e questionadores. Para buscar este diferencial, pretende-se demonstrar neste trabalho, a importância da contribuição do cinema, e de sua linguagem especial de construção de imagens, de expressão cultural formadora de realidades, de valores e de visões de mundo, para enriquecimento de uma docência jurídica de qualidade.
\end{abstract}

Palavras-chave: Educação, Cinema, Ensino Jurídico

Abstract: It is urgent to think about the didactic and pedagogical approach of the professor in the Law courses. Traditionally, this professor tends to be formalist, and the legal practice needs new ideas and conceptions in order to be less dogmatic, less repetitive, less ritualistic. Legal teaching contributes to create and maintain the traditional conceptions of the legal phenomenon. A broaden approach of the Law, argumentative and reflective, may be achieved by making changes in the traditional teaching, which is usually based on expository lectures. The Law Professor must be an agent and subject of an educational process which builds knowledge and leads the students to criticism and questioning. In order to search for this approach and enrich the legal teaching, this issue intends to demonstrate the importance of the cinema and its special language in building images, in expressing culture and reality, values and world views.

Key-words: Education, Cinema, Legal Teaching Introdução

Em artigo publicado no jornal "O Estado de São Paulo" ("Muito Direito, Pouca Justiça", 3/9/2014, p. A-2), o Presidente do Tribunal de Justiça de São Paulo, Desembargador José Renato Nalini, faz sérias e fundamentadas críticas ao ensino do direito no Brasil, creditando-lhe algumas consequências nefastas para a administração da Justiça, entre elas a multiplicação das demandas judiciais.

\footnotetext{
* Mestrando em Filosofia do Direito pela Pontifícia Universidade Católica de São Paulo (PUC-SP). Formado em Direito pela mesma instituição. Professor do Curso de Direito do Centro Universitário Assunção (UNIFAI).
} 
A partir da constatação evidente da proliferação de cursos de direito que, no Brasil, "superam em número a soma de todas as outras existentes em todos os demais países da Terra", o autor ressalta o equívoco da perspectiva adotada para o ensino jurídico:

O ensino do Direito durante longo tempo se confundiu com o aprendizado de textos legais. (...) A insuficiente compreensão do fenômeno jurídico gerou a profusão de Faculdades de Direito. (...) A disseminação do ensino do Direito registrou um subproduto hoje considerado indesejável: a multiplicação de demandas judiciais, a judicialização da vida brasileira.

Embora não se possa creditar unicamente ao ensino jurídico as reconhecidas dificuldades da prestação jurisdicional, pois com elas contribuem concomitantemente os exagerados formalismo e procedimentalismo que informam a estrutura burocrática judiciária, originária da histórica tradição bacharelesca brasileira, a ênfase distorcida na redução do Direito ao texto positivado demanda uma reflexão sobre as práticas educacionais do ensino jurídico, pois como assevera o autor mencionado:

Já passou da hora de reformular o ensino jurídico. (...) A 'era dos direitos' não pode ser confundida com a 'era das leis'. O Direito é um fenômeno muito mais abrangente que a literalidade

E assim conclui o artigo:

A intensificação dos litígios somente evidencia o mau uso da ciência jurídica. Sobram leis num Brasil onde a injustiça é flagrante.

No contexto abordado pelo autor, há que se inserir a responsabilidade do professor de direito como agente e repetidor dessas distorções pedagógicas, filosóficas e científicas, que contribuem para dificultar a prática de um ensino jurídico de qualidade e uma docência competente, necessárias à sua reformulação que, como visto, já se faz tarde.

Pretende-se, então, neste trabalho, trazer algumas contribuições para a reflexão sobre a didática e a pedagogia do professor de direito, sua capacitação para atuar no processo educacional atual, que demanda novas habilidades e competências, além de uma reavaliação metodológica do ensino jurídico.

O que é proposto é qualificar o docente do direito como agente e sujeito de um processo educacional, de construção coletiva de saberes, e não um simples repetidor de causas assentadas e de ideias e conceitos preestabelecidos, que não permitem espaço para o questionamento, para a discussão e para a reflexão crítica do fenômeno jurídico. 
Para tanto, faz-se necessária uma breve abordagem da educação e do ensino e da experiência docente na construção de valores, visões de mundo, concepções de direito em conjunto com o aluno.

Mais: a dialética pedagógica pretendida ressalta a importância do uso de técnicas e estratégias que podem ocupar o espaço da vetusta e tradicional aula expositiva ou da repetição de seminários, fichamentos, resumos e exercícios torturantes de memorização de conceitos e de textos normativos, completamente desarticulados e despregados do mundo real.

Neste ponto, a partir da reflexão de que o direito é um discurso constituidor de realidades, como texto e linguagem que é, busca-se na linguagem especial do cinema, uma contribuição ímpar para a apreensão e compreensão dos fenômenos jurídicos, que são, inegavelmente, também produtos de cultura humana.

O cinema - expressão cultural e de linguagem - pode ser inserido em sala de aula para estabelecer novas relações de construção do conhecimento, justamente por expressar-se predominantemente pela imagem, pelo afeto, ao traduzir expressões e visões de mundo pelo texto imagético.

Pode-se, então, pela articulação entre o direito, o cinema e a educação, traçar algumas breves considerações sobre as possibilidades do uso do cinema (e dos filmes) para o ensino do direito, e contribuir para uma docência jurídica de qualidade.

\section{Direito: linguagem constitutiva de realidades}

Para um ensino jurídico de qualidade, faz-se necessária uma conceituação de Direito que ultrapasse a visão limitada e reducionista de que "direito é lei", simplesmente como norma positivada. Assim, pode-se partir de uma concepção de direito como fenômeno cultural e histórico que se expressa por meio de uma linguagem.

O direito é, pois, uma das expressões da cultura humana que dispõe de linguagem própria e especial. O direito não descreve coisas, nem objetos físicos e materiais que possam ser empiricamente observados.

Como linguagem - experiência humana por excelência - é produto de embates, de ideias, de concepções e valores do grupo social em que se situa. E somente a partir deles é que é elaborado o discurso jurídico.

Neste sentido, afirma José Reinaldo de Lima Lopes: 
O discurso jurídico que incorpora a definição do direito é constitutivo da realidade. Casamento, contrato ou república não são objetos materiais: são sentidos intersubjetivamente aceitos (neste aspecto, objetivos) de ações reais. (...) A constituição do direito não é a descoberta de alguma coisa já feita: é a invenção de uma realidade social, cuja existência dá-se apenas na esfera das interações e ações humanas. (Lopes, 2004, p. 29-30)

Não é outra a lição de Gregório Robles:

\begin{abstract}
Mediante o texto jurídico, o grupo humano (...) se constitui e se revela, comunicandose com os membros para exigir-lhes organização e condutas. (...) O texto jurídico é um texto prescritivo (...) cujo sentido intrínseco é dirigir, orientar ou regular as ações humanas. Além disso, o próprio texto cria as ações que podem ser qualificadas como jurídicas(...). Por estranho que possa parecer, o homicídio como ação jurídica só existe depois que o texto jurídico prescreve o que é que se deve entender por homicídio. A ação física de matar alguém existe independentemente do texto, mas a ação jurídica definida como homicídio só é possível em razão da preexistência do texto jurídico. (Robles, 2005, p.28-29)
\end{abstract}

A partir desta concepção, a simples ensinança da lei como realidade única do direito, ou a mais especial, não dá conta da complexidade e amplitude do fenômeno jurídico como constituidor de uma realidade social. O ensino jurídico precisa adotar uma visão e adotar uma prática que permita vislumbrar sua dimensão comunicacional e de linguagem especial.

O texto, como expressão humana, contém e produz valores de "cultura" que, por abarcar os sentimentos, pensamentos e desejos do homem, corresponde ao que Miguel Reale conceitua como sendo "a unidade sintética de todos os objetos do conhecimento e das criações da espécie humana" (Reale, 2000, p.17).

\title{
Competência para ensinar direito
}

Para ensinar o direito, o docente deve atentar para esta concepção dinâmica do fenômeno jurídico. Dinâmica, sim, porque não pode estar amarrada a um momento passado, posto que os valores e os desejos humanos alteram-se no tempo e lugar: há novas realidades a serem constituídas para novas necessidades sociais, motivadas por novos pensamentos, novas concepções de mundo e de homem.

Como bem lembra Norberto Bobbio, "os direitos do homem (...) são direitos históricos (...) nascidos de modo gradual, não todos de uma vez e nem de uma vez por todas" (Bobbio, 2004, p.5).

O direito não é sagrado. Pode ser questionado e refletido criticamente e ensinado a partir desta perspectiva. Para tanto, há que se exigir competência do professor de direito. 
Por competência, adota-se aqui a conceituação de Terezinha de Azerêdo Rios, que a entende como um "conjunto de saberes e fazeres de boa qualidade" (Rios, 2010, p.87) e para quem:

A competência (...) guarda um sentido de saber fazer bem o dever. Na verdade, ela se refere sempre a um fazer, que requer um conjunto de saberes e implica num posicionamento diante daquilo que se apresenta como desejável e necessário. É importante considerar-se o saber, o fazer e o dever como elementos historicamente situados, constituídos pelos sujeitos em sua práxis. (Rios, 2010, p.88).

Saber ensinar é mais do que reproduzir simplesmente lições passadas e conhecimentos cristalizados. Para ensinar, o professor de direito não pode limitar-se a ser um bom profissional em sua área de atuação jurídica (como juiz, advogado, promotor), e que também dá aulas. Carece fazer-se professor de qualidade, que está sempre em processo, sempre se construindo e se reconstruindo cultural e historicamente.

O ensino do direito, no sentido já visto de expressão cultural humana e fenômeno de linguagem, demanda um professor crítico em suas práticas, com o domínio de conteúdos sim, mas atento às transformações sociais que impactam a realidade normativa e que devem transformar as constituições desta realidade.

O professor, neste contexto, não se limita a transmitir conceitos ou dogmas, mas é sujeito deste processo educacional. Constrói imagens de valores e de concepções de mundo em conjunto com seus alunos.

Nem professor nem aluno podem ter assim uma posição passiva no processo: ambos são sujeitos e agentes, constroem-se mutuamente por meio da linguagem comunicacional do texto.

Este processo caracteriza-se por disposições críticas e reflexivas de seus partícipes e, em especial, do professor que:

(...) utiliza todos os recursos de que dispõe - recursos que estão presentes ou que se constroem nele mesmo e no entorno - e o faz de maneira crítica, consciente e comprometida com as necessidades concretas do contexto social em que vive e desenvolve seu ofício. (Rios, 2010, p.107)

\section{Educar: processo coletivo de socialização}

O processo educativo desenvolve a construção conjunta de saberes, que supera a mera transmissão de informações. Na realidade, construir saberes é organizar as informações e sobre elas refletir criticamente. 
O conhecimento e o saber originam-se, então, de dinâmicas constantes que atuam simultaneamente entre professor e aluno: é uma experiência coletiva de socialização.

Ensinar é uma das formas de educar, pelo menos na sua vertente formal e situada especialmente no espaço escolar, e também um processo de socialização porque nele o aluno não só interioriza regras e valores do grupo em que está inserido, mas ultrapassa esta dimensão para ter uma participação ativa e em permanente construção "em que os protagonistas são agentes e produtos da interação social - os indivíduos se socializam produzindo o social”, no dizer de Rosália Duarte (Duarte, 2002, p.15-17).

É pela educação que são transmitidas e assimiladas as concepções culturais de direito, de justiça, de ética, de moral, que servirão de referência para atuação social do aluno e do professor.

\section{$O$ cinema ensina}

A partir da concepção de que ensinar - uma das formas de educar - é criar, fixar, mostrar valores, modos de vida e visões de mundo, que pode receber contribuições da literatura, do teatro, da música, enfim de todas as artes, pode-se aqui incluir a inegável possibilidade de participação do cinema no processo educativo.

A atividade educacional, no seu espaço mais tradicional - a sala de aula -, é por excelência um ambiente de discurso e, pois, de linguagem, de texto promovido pelo professor diante de um auditório cativo de alunos.

Similarmente, o cinema opera num espaço onde se diz algo, embora por imagens, sons, luzes, música e silêncios. A conjugação dessas técnicas tem um efeito arrebatador no espectador, talvez com maior intensidade do que uma aula comum.

A diferença é produzida pelo efeito imagético do cinema: o envolvimento sensível do espectador, a captura do seu inconsciente, de seus sentimentos e emoções, mais eficiente e rápido do que o discurso meramente verbal.

Neste processo individual e ao mesmo tempo coletivo as concepções da vida social, os valores culturais são também transmitidos e recepcionados pelo espectador sem intermediação imediata da razão:

Parece ser desse modo que determinadas experiências culturais, associadas a uma certa maneira de ver filmes, acabam interagindo na produção de saberes, identidades, crenças e visões de mundo de um grande contingente de atores sociais. Esse é o maior 
interesse que o cinema tem para o campo educacional- sua natureza eminentemente pedagógica. (Duarte, 2002,p.19).

A linguagem cinematográfica é complexa. Utiliza técnicas para provocar emoções no espectador. Esta característica afetiva do cinema, que envolve o auditório, suspende momentaneamente as noções de tempo e lugar, de tal forma para atuar num campo privilegiado sem intermediação da razão. O cinema impacta emocionalmente para produzir o que Júlio Cabrera denomina de "conceito-imagem":

Os conceitos-imagens do cinema, por meio desta experiência instauradora e plena, procuram produzir em alguém (um alguém sempre muito indefinido) um impacto emocional que, ao mesmo tempo, diga algo a respeito do mundo, do ser humano, da natureza etc. e que tenha um valor cognitivo através de seu componente emocional. (Cabrera, 2006, p. 22).

Nesta linha de reflexão, o autor aponta para o efeito que tal abordagem produz no espectador, qualificando-o de "logopático", ou seja uma apreensão lógica, racional, e pática, emotiva, ao mesmo tempo. O emocional, para o autor, não exclui o racional:

(...) certas dimensões fundamentais da realidade (ou talvez toda ela) não podem simplesmente ser ditas ou articuladas logicamente para que sejam plenamente entendidas, mas devem ser apresentadas sensivelmente por meio de uma compreensão 'logopática', racional e afetiva ao mesmo tempo. (Cabrera, 2006, p.20).

O processo de conhecer o mundo - objetivo primeiro do atuar pedagógico - pode se valer do cinema nesta perspectiva sincrética entre emoção e razão. Há saberes "indizíveis" que são desenvolvidos pelo afeto, pelos sentidos, para, somente depois, serem apreendidos pela razão:

A racionalidade logopática do cinema muda a estrutura habitualmente aceita do saber, enquanto definida apenas lógica ou intelectualmente. Saber algo, do ponto de vista logopático, não consiste somente em ter 'informações', mas também em estar aberto a certo tipo de experiência: em 'deixar-se afetar' por uma coisa de dentro dela mesma, em uma experiência vivida. (Cabrera, 2006, p.21)

Ressalta, pois, a riqueza e potencialidade da utilização do cinema no processo educacional: uma aprendizagem sensível e certamente muito rica, que enseja a análise crítica do mundo, da realidade social, dos valores humanos da vida, enfim de todos os valores da educação. 


\section{Direito e educação pelo cinema}

É neste ambiente de construção coletiva de valores caracterizador do processo educacional que se insere o cinema e como contribuidor para a qualidade do ensino jurídico.

Se o professor de direito se quer competente para que o ensino ultrapasse a repetição dogmática de concepções de lei que reduzem e limitam o estudo do fenômeno jurídico, não pode desprezar a rica contribuição que o cinema pode prestar à educação jurídica.

Tal como o direito, o cinema expressa-se por meio de uma linguagem especial que também constitui uma realidade no espectador, e o faz apresentando valores e concepções de (e para o) grupo social. Filmes também geram conceitos, no dizer de Júlio Cabrera:

(...) na medida em que a mediação impactante da sensibilidade - afeto - conduz à formação de uma estrutura captadora - descritiva - organizadora do mundo com pretensão (em geral frustrada!) de verdade e universalidade (Cabrera, 2007, p.17).

Neste processo de educação, tanto o direito quanto o cinema traduzem-se como constituidores de realidades, mediados por uma linguagem especial e de comunicação. Assim como o direito qualifica uma ação predicando-a como juridicamente relevante, no entender de Gregório Robles (2005), o cinema constitui realidades mediadas pela linguagem afetiva, emotiva e que impacta a razão.

Segundo Júlio Cabrera:

O cinema tem um mecanismo predicativo próprio, vinculado com suas particulares possibilidades expressivas. Ele é uma linguagem porque se cerca de algo. (Cabrera, 2007, p.22).

A linguagem constitutiva do direito e do cinema podem atuar juntas no processo educacional de modo a qualificar o ensino jurídico e a atuação de um professor mais competente. A aula de direito poderá ser rica, boa e bela.

\section{Conclusão}

Educar - e o ensino jurídico é espécie de educação - é construir imagens de valores, visões de mundo, representações, em um processo coletivo que demanda participação conjunta - cúmplice - de professores e alunos. 
O cinema, não apenas filmes, nem muito menos apenas filmes de julgamentos, pode dizer muito ao direito e do direito, na medida em que provocar reflexões sobre as concepções jurídicas das realidades sociais.

No cinema, não só pelo que é visto, mas também pelo que não é visto, a imagem é criada no (e pelo) espectador, imagem construída com emoção, com afeto, pelos sentidos.

A aula de direito, mediada por um professor competente, que domine os conteúdos da disciplina, e que faça uso do cinema como fonte de expressões de visões de mundo e de homem, num processo de construção coletiva com o aluno, pode adquirir uma qualificação especial, uma eficácia maior.

Com o cinema, o ensino jurídico poderá libertar-se de suas amarras livrescas e dogmáticas, para lançar-se num espaço saudável de questionamentos, de perguntas e de imagens. Com o cinema, a aula de direito será de construir imagens.

\section{Referências bibliográficas}

BOBBIO, Norberto. A era dos direitos. Rio de Janeiro: Elsevier, 2004.

CABRERA, Júlio. O cinema pensa: uma introdução à filosofia através dos filmes. Rio de Janeiro: Rocco, 2006.

. De Hitchcock a Greenaway pela história da filosofia: novas reflexões sobre cinema e filosofia. São Paulo: Nankin, 2007.

DUARTE, Rosália. Cinema \& Educação. 2. ed. Belo Horizonte: Autêntica, 2002.

NALINI, José Renato. Muito direito, pouca justiça. In: O Estado de São Paulo, 3.9.2014. p. A-2.

LOPES, José Reinaldo de Lima. As palavras e a lei: direito, ordem e justiça na história do pensamento jurídico moderno. (Coleção Direito GV): São Paulo: Editora 34/Edesp. 2004.

REALE, Miguel. Cinco temas do culturalismo. São Paulo: Saraiva, 2000.

RIOS, Terezinha Azerêdo. Compreender e ensinar: por uma docência da melhor qualidade. 8. ed. São Paulo: Cortez, 2010.

ROBLES, Gregório. O direito como texto: quatro estudos de teoria comunicacional do direito. Barueri, São Paulo: Manole, 2005. 